\title{
"If the shoe ain't your size, it ain't gonna fit": Ideologies of Professional and Marital Instability among US White-Collar Workers
}

\author{
Carrie M. Lane
}

Most scholars in the humanities and social sciences are comfortable, or at least familiar, with a certain degree of uncertainty in their work. Our subject matter rarely lends itself to tidy, verifiable conclusions; instead, particularly in the wake of postmodern critiques, our scholarly works almost always include a nod to the unknown, the yet to be studied, the likelihood that the passage of time will bring complication, revision, and, occasionally, retraction. This is perhaps doubly true for ethnographers, whose scholarship is based on participant-observation, openended interviews, and the analysis thereof, and lies somewhere along the blurry border between the humanities and social sciences. As Clifford Geertz has said:

It is a strange science whose most telling assertions are its most tremulously based, in which to get somewhere with the matter at hand is to intensify the suspicion, both your own and that of others, that you are not quite getting it right. But that, along with plaguing subtle people with obtuse questions, is what being an ethnographer is like. (29)

We ethnographers are perhaps more comfortable than most with this reality. It is, to put it simply, the nature of human beings to lead messy, complicated, ever-changing

Carrie Lane is an Assistant Professor of American Studies at California State University, Fullerton, where she teaches courses on ethnography, cultural history, community studies, white-collar work, and the theories and methods of interdisciplinary research. Dr. Lane is currently completing a book on unemployment and jobseeking in the U.S. high-tech industry. She is also conducting research for two new projects, one on cultural narratives of the housing crisis, and a second on the simple living movement. 
lives, and to talk and think about those lives in messy, complicated, ever-changing ways. Those of us who study human culture learn to accept, however begrudgingly, the inherently partial, mutable, and debatable nature of our findings, despite what tangible steps we might take to minimize those aspects of our work. ${ }^{1}$ Yet accepting on a philosophical level what George Marcus has called "a norm of incompleteness" (356) is a quite different thing from witnessing, as I recently did, the havoc such realities can wreak on one's efforts to make the sort of claims and conclusions on which scholarly reputations and careers are built.

Ultimately, this article has two arguments. In crafting the first, I draw on extended ethnographic fieldwork to document and explore connections between how unemployed white-collar high-tech workers in the first decade of the twenty-first century made sense of their increasingly insecure careers and how they made sense of their increasingly strained marriages. Complicating received wisdom about the inevitable "crisis of masculinity" that accompanies job loss, I demonstrate that many white-collar jobseekers saw themselves not as dependent employees victimized by economic and political trends beyond their control, but as masculine, independent entrepreneurs navigating an increasingly competitive but ultimately fair labor market. This perspective represents a significant break from how previous generations of white-collar workers understood their work and the loss thereof, and demonstrates the need for new scholarly frameworks for thinking about both the structure and cultural meaning of work and unemployment. This worldview also had dramatic personal and political implications for tech workers. Although framing unemployment as natural and inevitable eases some of the psychological burdens of unemployment, it also erases corporate employers' and pro-corporate government policies' roles in dismantling the social contract of employment. As well, the valorization of the flexible, autonomous entrepreneur obscures the reality that most tech workers survived periodic bouts of unemployment not through their wits and wiles alone, but by relying on the financial support of employed spouses, a situation made possible by the national rise in dual-career couples and palatable by shifting cultural ideals of masculinity and marriage. Once again, however, framing reliance on a working spouse as natural mitigates certain hardships traditionally associated with unemployment, particularly for men, but implicitly sanctions the transfer of responsibility for managing insecure employment away from the corporation or the state onto individual families, many of which, as I demonstrate, eventually falter and fail under that increasingly heavy burden.

In the course of presenting my research findings, I also describe my experience of having to revisit and revise my previous (and published) conclusions in light of a series of follow-up interviews I conducted long after my initial fieldwork. Although this process ultimately strengthened and deepened my analysis, it also caused more than a little stress and self-doubt, particularly as it revealed certain weaknesses in my original research design. My second argument, then, is that experiences like mine of "not quite getting it right" can illuminate the unique challenges of ethnographic fieldwork while also demonstrating, in tangible, accessible ways, the inherently partial and incomplete nature of all cultural analysis. Openly discussing such experiences, while humbling, can serve to both instruct and reas- 
sure ethnographers, particularly the neophytes among us, by reminding us that we, like our scholarship, are fallible, mutable, and often surprisingly resilient in the face of challenges and change.

In the summer of 2009, I was putting the finishing touches on a book manuscript about U.S. high-tech workers who lost their jobs during the economic downturn of the early 2000s. In that book, A Company of One (forthcoming), I investigate how these workers experience and make sense of the work they do and the loss thereof. I decided to open my conclusion with a "where are they now?" update on nine interviewees whose stories figured prominently in the preceding chapters. My original fieldwork was conducted between 2001 and 2004 in Dallas, Texas, and included open-ended interviews with 75 jobseekers, some of whom I met with multiple times over a four-year period. I had stayed in touch by e-mail with a few participants over the years, but it had been about five years since I had spoken with most, and I was curious - and a bit nervous - to learn how they had fared, professionally and personally, in the intervening years. That the nation was in the throes of yet another economic downturn at the time heightened the project's relevance, but also made it all the more likely that some of the tech workers I had met nearly a decade before might be facing yet another bout with job loss and unemployment.

One of the central findings of my research had been that today's white-collar U.S. workers embrace a very different model of work and career than did previous generations. Since the dramatic expansion of the white-collar workforce in the late nineteenth and early-twentieth centuries, the social contract of employment for middle-class, usually male, office workers was that, in exchange for hard work and loyalty, corporate employers would provide salaried employees with a middle-class standard of living, a paternalistic package of benefits (including such disparate elements as pensions, stock options, health care, pretty secretaries, and annual picnics), and, most importantly, secure, life-long employment (Davis; Kwolek-Folland). For much of the twentieth century, for the most part that contract held; while layoffs were routine, albeit usually temporary, for blue-collar workers, their white-collar counterparts enjoyed relative professional security. When that began to change in the $1970 \mathrm{~s}$, as companies adopted "lean and mean" management strategies that included regular downsizings, many white-collar workers felt misled and betrayed by the companies to which they had dedicated years, often decades, of loyalty and hard work.

By the early 2000s, however, most white-collar tech workers held a very different set of expectations of their employers. As they explained it, job loss and periodic unemployment were not anomalous, unexpected events, but natural and inevitable components of modern professional life. These workers never expected to stay with a single employer for life; most had changed jobs many times already, voluntarily and involuntarily, and many had worked at various times as contractors, consultants, or entrepreneurs. As they saw it, a successful career was one to be culled together from a variety of positions, and their primary objective was not to stay employed, but to stay always employable, ready to change positions, and even professions, at a moment's notice. Thus while they were by no means happy about being laid off, they rarely expressed the sense of shock, betrayal, and self-blame so prevalent among managers downsized in the 1980s, as described in Newman (42-94). These 
twenty-first century tech workers, most of whom came of professional age after the social contract of employment had already been dismantled by frequent layoffs and the rise of contingent labor, believed that expecting an employer to provide secure, long-term employment these days was a fool's errand.

During the eighties, companies realized they don't have any loyalty to their employees anymore. During the nineties, employees realized they don't have any loyalty to their companies anymore... If a company has a need for my skills and I can supply that to them, they hire me. When that need is over with, when they don't need me anymore, sure, I'm terminated. And I was just having, I'll say a discussion but it was really an argument with good, good friends of ours over the weekend, and they're still thinking in that old mode. And that old mode doesn't exist anymore. They're saying, "oh, but it's so terrible to have people working at a company 20 years and then they lay them off." Yeah, [obviously it is terrible]. What's your point? I don't know any company, where it's in their charter, where it's in their goal as a company, to provide employment to people. You know, it's just not there. They're in business to provide a service or a product. They're not in business to hire people. (Phil Wright ${ }^{2}, 47$, consultant to startup technology companies)

Going out and looking for a job, it's a sucker's game. You'll keep it as long as they want to let you have it. That's easy to say. A lot of people are more than happy to go and do the nine-to-five gig and go home and not worry about it but they are liable to be a victim. They will be victimized because they allow themselves to be. (Mike Barnard, 49, digital media specialist)

I think some employees sometimes complain that their career growth isn't managed here [at his current, post-layoff employer]. That always annoys me because I feel like, you guys aren't children. You need to manage your own careers. We can help you, but if you don't take responsibility for your career growth then you're hurting yourself. Why should a company have to do that for you? ... People say, "Well, I gave the company ten years, blah, blah, blah, blah, blah." Look, they paid you for those ten years, so I think you're even, you know? (Daniel Klein, 28, software developer)

In the quotations above, tech workers not only argue that the days of life-long employment at a single company are over, they lay claim to a particular form of masculine agency. Framing secure, long-term employment as a weak and dependent state, they manage, even while unemployed, to position themselves as progressive, independent agents. They invoke the foil of the organization man, whose loyalty and yen for security now mark him as an outmoded thinker, willing victim, or annoying child. Through the individualistic, pro-market discourse of neoliberalism (the origins and sway of which are described in Frank and Harvey), unemployment is transformed into a state of relative autonomy in which the jobseeker is 
not a failed would-be dependent, but, in the tech workers' own words, a flexible "company of one," prepared to compete, and to win, on the idealized playing field of the free market.

In my book, I argue that this perspective softened some of the potentially emasculating effects of job loss and prolonged unemployment for male jobseekers. By conceptualizing themselves as valued professionals despite the absence of paid employment (a perspective that, I argue, regular participation in organized networking events for the unemployed not only encouraged but ritually reinforced), these workers sidestepped, at least to some degree, many of the emotional and social hardships traditionally associated with unemployment. Yet this model of work had other, less positive effects. First, this unrelentingly individualistic worldview rendered essentially invisible the possibility of more public and collective responses to insecure employment and inadequate social provisions for the unemployed. As well, it obscured the extent to which these jobseekers' material advantages, most of them unique to the educated middle and upper classes-including access to credit and well-paying, if not high status, interim positions - made possible the embracing of this more "flexible" approach to unemployment.

Finally, and most relevant to the discussion at hand, this framing of jobseekers as self-reliant companies of one, in contrast to dependent employees, ignored that most tech workers in this study were in fact members of two-income households. ${ }^{3}$ Thus their ability to weather prolonged unemployment, financially and emotionally, and to hold out for professional positions was in fact due more to their dependence (on a spouse's income) than to their independence. Yet when they discussed their working spouses, to whom they were outspokenly grateful, male jobseekers drew on revamped models of masculinity and marital partnership to frame their reliance on a wife's income as evidence of their manhood, rather than a challenge to it. When I spoke to 58-year-old Ed Donnelly in 2004, for instance, he had been looking for a computer programming position for nearly four years while working part-time at an electronics store. His wife, he said, "has gotten a pretty decent job, so she is basically the breadwinner in the family and I am struggling to pay my share of the expenses. And unlike a lot of guys I don't have a problem with me having the lower income." Conceptualizing his willingness to rely on his wife's income as evidence of his non-sexist views, Ed implicitly contrasts himself to those less secure or less progressive men who might be intimidated by such a situation.

Other male jobseekers explained their reliance on spousal income as the natural product of the ever-shifting division of labor within marriages based on egalitarian partnerships. ${ }^{4}$ While he looked for full-time work in high tech, Enrique Vivar, a 35-year old project manager, had taken on two part-time jobs (unloading trucks at a furniture warehouse and teaching Spanish at night school); his wife, a homemaker since their first child's birth five years before, had also taken on two part-time positions, and the two now shared responsibility for childcare and domestic work. Of their marriage, Enrique said, 'It's not a marriage for convenience, you know, where I'm going to provide and she's going to care for the kids. It's a marriage for love." Enrique explicitly rejects the model of the provider husband and dependent wife, drawing on the discourse of romantic love, rather than material exchange, to 
recast theirs as a natural, even morally superior division of responsibilities.

Many married male jobseekers shared Enrique's conviction that the division of labor within modern marriages need not fall along traditional gender lines. Since his layoff from a once-hot web design firm, Alex Brodsky, 40, had taken on responsibility for "doing laundry, running whatever errands needed to be done, paying the bills, taking care of all the domestic things that go into keeping a household running. Because I was the only one available and that was a job that I was able to do." Meanwhile, his family, which included Alex, his wife, and their young daughter, was living off his wife's salary as a high school teacher.

This isn't my first time being unemployed. ... And again that's put a big burden on [my wife]. She supported me through that. That's the key to it. She has taken on incredible burdens to help me to do the things that I need to do. Not to her complete detriment to the point that she completely loses [her] identity, but knowing that we're both working towards something. I'm doing my part, she's doing her part. (Alex Brodsky, 40, Information Architect)

Like Enrique's, Alex's framing of the division of financial and other responsibilities within his marriage rejects the model of provider and dependent. Although his wife earns most of the family's income, Alex does not see himself as a dependent, with all the emasculating implications such positioning might incur. Instead, he sees himself contributing in equal if unpaid ways, a statement that reflects the extent to which U.S. ideals of manhood and fatherhood have altered over the previous thirty years.

Ed, Enrique, and Alex all draw on narratives of successful manhood that are themselves the relatively recent products of decades-long cultural and social shifts around feminism, family, and masculinity - the enlightened husband comfortable with his wife's professional success; the romantic who wants a partner, not a Stepford wife; the doting father who willingly shoulders the second shift of domestic and childcare responsibilities. These images complicate the long-standing presumption that U.S. men's identities are grounded entirely in paid labor and financial provision, and support Nicholas Townsend's argument that U.S. men actually make sense of their lives through a "package deal" of interconnected elements, including fatherhood, marriage, employment, and home ownership. In and of itself, this represents a radical departure from the experiences of previous generations of displaced white-collar American men, whose identities were tethered so tightly to secure paid employment.

Based on these findings, in 2009 I published a research article in which I argued that changing norms of middle-class masculinity, shifting structures of white-collar employment, and the rise of dual-earner families had combined in such a way that jobless men were now able to retain a sense of themselves as independent, masculine professionals despite increasingly long periods of unemployment, underemployment, and reliance on spousal income. I also noted, however, that these changes had occurred alongside, and, in some ways, facilitated, the transfer of responsibility for managing the increasingly heavy burdens of insecure employment and a social safety net weakened by neoliberal policies onto the shoulders of dual-income families. 
It was only shortly after I sent that article to press that I reconnected with my primary informants for follow-up interviews. My central objectives were to discover whether they had retained their faith in the ideology of career management over time, and to determine how well that belief system had served them, professionally speaking. On the former question, the response was essentially unanimous; on the latter, it was decidedly less so. Five years out, nearly every jobseeker maintained a dogmatic faith that managing one's career, eschewing long-term employment at a single firm, and remaining always on the lookout for the next job was the best, indeed only, way to achieve professional success. Even those who had not been particularly successful on the labor market remained nonetheless committed to the notion that professional and financial rewards awaited those who navigated the job market as self-reliant, optimistic companies of one. With very few exceptions, they were firmly against organized political action on behalf of the unemployed (this was true even among those who were themselves again unemployed in 2009), and saw the individual as ultimately responsible for his or her professional fate, even during the worst recession in decades. When they did articulate frustration with the worsening economy, weak labor market, and lack of adequate support for unemployed persons, interviewees either opined that there was nothing they or other Americans could do to alter the situation, or espoused wholly individualistic solutions, such as remaining positive, networking, scaling back household expenses, or helping others.

The consistency of tech workers' responses over time reinforced my initial assessment of how central the ideology of career management is to their perspectives on work and unemployment. It also answered, at least in part, a lingering question about the resiliency of that worldview. Upon reading the dissertation upon which my book is loosely based, one of my advisors asked me what I thought the "shelf life" of this optimistic, individualistic perspective on job loss would be. He suspected, and others have since echoed him in this, that the passage of time, and the continuing scarcity of full-time professional work, would erode jobseekers' faith in the promise of a self-managed career. Were I to stay in the field a few more years, it was suggested, I would witness the unraveling of this system of beliefs and the rise of a more critical and politically charged perspective on corporate employers and the demise of job security. Certainly, there are Americans who have embraced just such a position as their time out of work wears on, their savings dwindle, and the gaps in their resumes grow ever more glaring. Yet, as others have acutely noted and usually lamented (e.g., Ehrenreich; Greenhouse; Venkatesh), American labor has an incredibly long fuse; these high-tech workers, steeped as they are in a broader culture of antipolitics that "dismisses as futile both the discourse of critique and the call for social transformation" (Giroux 2), are no exception.

This finding is particularly noteworthy in light of how varied these nine jobseekers' professional fortunes had been over the preceding five years. Three of the tech workers I interviewed are reemployed at salaries higher than their pre-layoff positions; three are reemployed in full-time professional positions (one as an entrepreneur) but at a fraction of their previous income; one had moved through two managerial positions since we last spoke but was now unemployed again following another layoff; one never found another professional position and works a sales job 
for an hourly wage of $\$ 9$; and one (the only woman among the nine) left a new, well-paid professional position to become a full-time mother but is now pursuing contract positions to supplement her husband's income. Career managers were not wrong that the modern career is characterized by volatility; between them, from 2004 to 2009 the nine experienced four layoffs and more than a dozen job changes, not counting short contract positions. The resilience of their worldview, despite the financial and professional insecurity they have endured demonstrates that, while even former proponents such as Alan Greenspan agree that the neoliberal climate that engendered and sustained career management appears to be on its last legs, its ideological sway among white-collar Americans remains strong.

That consistency, as frustrating as it might be to those looking to unemployed workers to serve as the vanguard of social change, shored up my original findings, including my sense that, for its adherents, career management was never just a situationally convenient way of thinking; instead, it reflected and reinforced a much deeper and longstanding set of beliefs about the world and their place in it. Another pattern that emerged in my follow-up interviews, however, challenged some of my initial conclusions. Of the tech workers I re-interviewed (all of whom were heterosexual), seven had been part of a dual-earner household at the time of their job loss (two were married to each other), and two, both men, had wives who were full-time homemakers before their job loss but subsequently took part-time jobs while their husbands looked for work. By 2009, three of those eight marriages had ended or were, according to my interviewees, in the process of ending. Statistically, this is not necessarily significant. Nearly half of all marriages in the U.S. end in divorce. That more than a third of these marriages failed within the same five-year period, however, certainly seems significant. Even so, it was not so much that these marriages were ending, but the way in which interviewees discussed the demise of their marriages that most piqued my interest.

Those tech workers whose marriages were still intact continued to refer to theirs as egalitarian partnerships to which each spouse contributed in his or her own way. The three men whose salaries and statuses had improved over the previous five years expressed great appreciation for their wives' support during their time out of work. Two men's wives continued to work, while a third had retired from her executive position and was now supplementing her husband's income with her pension. Two of the men who had found full-time professional positions but taken significant pay cuts since their layoff remained married, but had altered the division of responsibilities within their marriages. The first, Daniel Klein, whose comments on his "childish" coworkers I quoted earlier, met his wife Natalie when they were both employed at a dotcom consulting firm. Following their layoffs (he was laid off approximately a year before she was) he found work quickly, but she struggled for nearly a year before finding reemployment. A year into her new job, which was both well paid and professionally rewarding, Natalie quit after giving birth to the couple's first child. Not only did they now have a child to support (and have since had another), but the couple went from having "a ton of disposable income" to living on Daniel's salary alone, a situation that became particularly challenging during the two months he spent out of work following yet another layoff in 2006. 
Despite Daniel's new role as sole breadwinner, the couple continued to conceptualize theirs as a partnership of equal contributors. Natalie explained:

I don't think there was ever a thought that [raising a child] was going to be easier [than paid employment], but it is so much harder! [Laughs] Holy cow! Physically and mentally, it's so much harder, And I think that took away so much of my concern or guilt or whatever about not earning physical cash, because there's no question about contributing to the family. It's just contributing in a very different way.

Daniel shared this perspective, emphasizing that Natalie's work in the home, while unpaid, was a job nonetheless.

She has her job, I have mine, meaning her job is to take care of the kids, while I go to my job, which is over there. There are definitely guys out there who are just like, she's spending your money, and blah, blah, blah. I just think that that's not a very healthy partnership.

By framing Natalie's domestic and childcare work as labor, albeit unpaid, that is akin to what Daniel does at the office, the couple retained a sense of their marriage as a partnership of equals even as they adopted a more traditional gendered division of familial responsibilities.

Another jobseeker, Keith Hartmann, experienced a similar, although steeper, decline in pay and status following his layoff. Following a job search that lasted nearly two years, Keith took a job overseas that, while extremely lucrative, meant living apart from his wife and three children. After one year, he left that position for a job in Texas that allowed him to return to his family, but was laid off almost immediately due to budget cuts. He spent the next eight months looking for work before landing a full-time job at a salary just a third of what he had been paid overseas. While Keith was unemployed, his wife, who had been a full-time homemaker for more than twenty years, took a part-time job in their children's school cafeteria to help pay the bills. She continued working even after he landed his new job in order to help make up for his lost salary. It was, Keith said, a difficult transition for her, but her willingness to take on that job, along with their children's unyielding support, are what Keith emphasized most when discussing his time out of work:

What I remember the most is how my family bonded together, and how we relied on each other, and not material things. ... Those are the kind of things that I will remember during that period, the good things that taught us character and persistence and not so much the financial stress.

Reframing the story of his unemployment and downward mobility into a narrative demonstrating the triumph of character over adversity, Keith manages to transform an externally imposed hardship into an opportunity to demonstrate his family's closeness and mutual support. His family's transition from one to two earners is 
celebrated as a demonstration of mutual support and commitment, rather than a necessary and sometimes painful response to circumstances beyond their control.

That the partnership ideal lives on in couples whose financial security has improved over the past five years is not surprising. That Keith's and Daniel's families retain that ideal despite multiple job losses and dramatic drops in household income testifies more powerfully to the model's ability to persist in challenging circumstances. The experiences of other jobseekers, however, those who fared similar to or worse than these men on the labor market, reveal the limits of that resilience in significant and disquieting ways, and point to aspects of the connection between how career managers think about work and how they think about their most intimate relationships that I had not fully explored in my previous analyses.

Mike Barnard, quoted earlier saying that looking for a job is "a sucker's game," was frustrated to find himself playing that game again and again following his layoff. After his division at a large media company was disbanded in 2001, Mike, then nearing 50, found full-time work as a contractor at another large corporation. Every time the company's quarterly earnings dipped below expectations, however, Mike and his fellow contractors were laid off, and then rehired weeks later after the company had "made their numbers." Mike quickly tired of being one of "the fall guys whenever there was a downturn." He had always wanted to start his own company, and decided that this was the ideal time to do it. His then-wife, who worked full-time, disagreed. Mike said:

I told my wife I was pretty sick of that and didn't see much of a future in it, and she was really insistent that I remained employed, as she saw it. It was probably one of the big issues, one of the tiebreakers on our marriage insofar in that I really was not wanting to go and continue to be a corporate whore, so to speak.

In describing his situation as that of a "corporate whore," Mike echoed previous characterizations of corporate employment as a feminized state of dependence. As he saw it, pursuing an entrepreneurial venture could serve as one means of reasserting his masculinity and independence in the face of a frustrating and disempowering situation. His wife, however, did not share his perspective on corporate employment, which she saw as the (relatively) secure alternative to entrepreneurship's risks. Yet in encouraging Mike to remain a corporate employee she denied him the one way he saw to reclaim his masculine agency. Ultimately, Mike chose to start his own company anyway (it is now in its fifth year and doing quite well), and the couple divorced.

Mike's was not the only marriage to become a casualty of insecure employment. The last time we spoke in 2004, Ed Donnelly, the programmer who "unlike a lot of guys" did not have a problem earning less than his wife, had been looking for a new programming job for nearly four years while relying on his wife's salary and working part-time at a big-box electronics store. He stayed at the electronics store far longer than he expected; when he ultimately left, it was not, as he had envisioned, for a new job in high-tech but for another sales job, this one at a gardening store (gardening was a long-time hobby of Ed's) where a better schedule, friendlier boss, and more satisfying work environment compensated for the lower hourly wage. 
When we reconnected in 2009, one of the first things Ed, then 62, told me was that his marriage was in the process of ending. In an initial email, he wrote:

I will go on to say, not as an appeal for sympathy but only as a data point for your book, that I am currently separated from my wife and do not expect a reconciliation. I don't think that my not having a good job was the only factor, but I do believe it was the most significant one. Ah, well, life goes on.

When we later spoke, Ed again drew a clear connection between the demise of his career and the demise of his marriage: "Because I'm not employed as well as I was and she is once again well employed, I don't feel like I'm contributing as much as I could be to the marriage. She said that she didn't worry about that, but her attitude seemed to say otherwise." Ed's own thoughts about his joblessness further fueled their difficulties. He said he was no longer as self-confident as he once was, and had lost hope of ever returning to the programming work he loves. He still saw marriage as a partnership to which one can contribute in meaningful ways even when unemployed, but, "If you can't contribute financially," he said, "you have an obligation to contribute other ways, and I couldn't keep up."

Though he sometimes got angry, both about his impending divorce and his inability to find professional reemployment, Ed, who was in 2009 "hanging on teeth and toenails, paying expenses and trying not to dig into my savings to do that," framed both hardships as the result of personal choices, rather than corporate decisions beyond his control.

Something goes wrong, you get angry. You don't have to have a rational reason for it. ... Intellectually, I know that I got paid well for what I was doing and it's my own fault that I didn't leave myself an out. The fact that my job skills are out of date is unfortunate from my perspective, but I consider it my own fault that I didn't see it coming and stay current so that I could jump to another job where I would have the current knowledge to keep working. That's my fault, not anybody else's.

Holding tightly to the individualist tenets of career management, Ed saw his career, like his marriage, as a casualty of his own failings, a perspective that, while hardly cheery, at least manages to recapture some sense of individual agency amidst a sea of insecurity and helplessness. ${ }^{5}$

Enrique Vivar, who declared his a marriage of love, not convenience, drew different but equally revealing parallels between the professional and personal hardships he had experienced over the previous five years. After more than a year of searching in the early 2000s, Enrique landed a position as a project manager approximately a year before I left the field. His wife then quit her part-time jobs to return to the role of full-time homemaker. Over the next few years, Enrique voluntarily changed jobs twice more, both times transitioning into higher paid positions that allowed him to work in his chosen field of international project management. In early 2009, however, Enrique lost his job due to budget constrictions and ongo- 
ing conflicts with his managers.

I could see the handwriting on the wall ... and I was scared, scared to the bones that I was going to get laid off. I didn't want it to happen because I knew that I had been laid off before and I was 14 months without a job and all that stuff, and I knew that the economy wasn't at its best right now, so I didn't want it to happen. I managed to hold onto my job for about eight months, but ultimately, if the shoe ain't your size, it ain't gonna fit.

Though his most recent layoff was clearly against his will, Enrique employed the metaphor of "fit" to reposition himself and his employers as equals, both seeking an ideal match. Had they been more compatible, Enrique suggested, he would still be employed, a claim that contradicts his own stated belief that job security is no longer attainable for U.S. workers. Asserting that his layoff was the natural result of incompatibility, however contradictory, allowed Enrique to avoid the emasculating conceptualization of himself as a helpless victim of a broader trend, aptly documented by Uchitelle, toward treating all employees, even experienced managers, as ultimately disposable.

This belief, that layoffs are both natural and a matter of individual, rather than structural, issues, is of course one of career management's central tenets, and to hear Enrique invoke it when discussing his layoff was hardly surprising. What did catch me off guard, however, was when he used the exact same metaphor to discuss his marriage, which had deteriorated significantly in the years since we last spoke.

After his most recent layoff, Enrique's wife Anna started her own business as an event planner to bring in money while he looked for work. Enrique, in turn, took on the bulk of the labor involved with running the household and caring for two children. While he enjoyed and took pride in these activities, the shift from primary breadwinner to co-earner and then to dependent spouse had been difficult for him.

I am really a proud Dad. I've got to tell you. I cook for everyone, I make sure that the house is clean for everyone. I take care of the cars, I take care of the finances. She takes care of her business, which, I have an MBA and just a couple of week ago I said, "You know, for the last year I've been doing your finances ... and last year you still lost about 15 grand. She goes, "No we didn't, if you consider the taxes and you paid my salary and everything." I was like, "Wait a minute. I've got an MBA. You don't know diddlysquat of how to run your business." And I'm giving you the short story of course. And we just don't know how to communicate with each other.

Enrique was proud of the ways in which he contributed to his family, and he drew an explicit parallel between those things he took care of (the cooking, the house, the cars, and the children) and that which Anna took care of (her business). In this sense, he was asserting the same partnership ideal of marriage that he and other male jobseekers invoked years before, in which each member contributes in his or her own different but equally valuable way. Yet Enrique was clearly not entirely 
comfortable with this division of responsibilities. After establishing his own business credentials ("I have an MBA"), Enrique goes on to question the profitability of Anna's business. When she rejects his assessment of her finances, and by association the value of his MBA, Enrique bristles, restating his superior qualifications and directly challenging Anna's ability to run a business. The problem, then, is not so much that the two "just don't know how to communicate," but that both are frustrated by their current situation and, more pointedly, that Anna refuses to accept Enrique's assertion that he, not she, remains the family's business expert despite the fact that her business income supports them all.

The extent to which Enrique's sense of self worth depends on Anna's validation is further demonstrated by his complaints about her refusal to acknowledge his work in the home.

I am a lot less stressed, Carrie, because Anna's got an income and now it's her turn to maintain us. And if she didn't have that income I'd be walking on the streets now, I'd be trying to do whatever needed to be done to pay the mortgage. Whereas right now because she's working I am taking care of the kids and I'm taking care of the house and I'm taking care of a lot of things, and I'm not dying. The only thing is where I tell my true friends, I don't mind doing it, but I do mind not being acknowledged for it. [Laughs] Now I sound like the wife. See how it sounds like the wife?

Enrique initially suggests that he is comfortable with, even relieved by, their current arrangement. He has done his part, and now it is Anna's turn to maintain the family. Yet his concluding joke suggests that Enrique feels emasculated by his dependence on his wife, both for financial support and for her acknowledgment of the value of his contributions to the family. He nervously laughs at the idea that he is playing the role of wife, not so much in terms of the labor he performs, but in the humiliating predicament of having to seek out, and not receive, affirmation of the value of his work.

Ultimately, though, Enrique reveals that it is not just Anna, but he, who doubts the value of his unpaid contributions.

Now she is the sole breadwinner, or bread provider, and I contribute what my measly workforce unemployment insurance will provide. [How do you feel about that?] I've been going back and forth. I'm okay with it. I just love being a lazy bum. I have become a lazy bum lately, just for the fact that it doesn't matter how hard I've tried, I haven't been able to make my wife and my family a hundred percent happy. And I shouldn't say my family, I should say my wife in general.

In the course of one interview, Enrique shifts from depicting theirs as a partnership of equal contributors, each taking care of different tasks, to one in which they "take turns" maintaining the family, and then, revealing his deepest fear, to one in which Anna is the breadwinner and he the lazy bum. Despite his proclamations of his domestic and business abilities, and his insistence that it is only fair that Anna now shoulder the burden of maintaining the family financially, here Enrique reveals the 
extent to which he, and perhaps Anna too, holds tight to a more traditional yardstick of masculinity, one according to which his current efforts fall far short of success.

All three of the men described above were, in their own way, trying to shore up their wounded masculinity, whether through entrepreneurship, continued jobseeking, or the embrace of domestic responsibilities, and all three believed their wives were undermining those efforts. Had Mike's wife endorsed his business idea, had Ed not suspected his joblessness was actually a factor in his wife's discontent, had Enrique felt that Anna appreciated his work in the home and shared his perception of theirs as an equal partnership, then these marriages, as these men see it, might have survived. That they did not is therefore framed as the result of personality conflicts and individual choices. Enrique made this particularly clear when at the end of our interview he said of his marriage: 'I've tried, I've tried, I've tried. It's just gotten to the point, I've stopped trying. It's time, because if the shoe ain't the right size, it ain't gonna fit." Employing the exact same metaphor to describe his looming divorce as he did when discussing his layoff, Enrique depicts as natural an event that is the product of specific economic circumstances and corporate business decisions. His and other male jobseekers' continued reliance on the neoliberal, individualistic ideology of career management, which I initially interpreted as a relatively effective if not necessarily ideal means of managing professional and personal transitions, prevents these workers from acknowledging that their marriages have been challenged and gradually weakened by the emotional and financial strain of multiple job losses, prolonged unemployment, financial hardship, and the demands of supporting a family. Attributing these difficulties to "fit" and personality renders invisible this alternative way of explaining, and attributing blame for, the unfortunate end of a marriage.

That unemployment strains marriages is not news; it is an oft-proclaimed truism that money (along with sex and parenting) is the most common cause of marital conflict. Indeed, I included examples of such tensions in earlier publications on this project, but prior to conducting these follow-up interviews I had not recognized the complicity of career management in disguising the role that economic and political circumstances beyond jobseekers' control had played in those conflicts. When I concluded that changing cultural norms around marriage and masculinity shielded married men's egos and identities from some of the harsher aspects of job loss and unemployment - something I still believe-I failed to examine whether their wives shared these views, or to investigate further the instances I did see of marital tensions resulting from prolonged joblessness.

My belated awareness of the extent to which tech workers' marriages were strained by job loss and unemployment, and the ways in which jobseekers co-opted the language of career management to explain their marital problems, was hidden, at least to a degree, by flaws in my initial research design. My focus had been almost exclusively on the jobseekers themselves and their regular participation in a vast web of networking and job search events geared to unemployed professionals. Although I noted a few instances of marital strife in my original interviews - including an early argument between Enrique and his mother-in-law over his familial responsibilities - that subject occupied a tangential space in my overall argument until an early 
reader of my dissertation brought its larger significance to my attention. Familiar as I am with research on the intimate interconnections and permeable boundaries between work and home life for white-collar workers (including Hochschild 1989; 2001; Nippert-Eng), I should have been more attuned to those connections and their significance, and should have interviewed more than the handful of spouses that I did. Ultimately, refocusing my attention on these issues led me to reverse some of my previous beliefs about the extent to which tech workers' ideas about work were connected to their ideas about marriage.

I was initially skeptical, for instance, of Richard Sennett's argument that the new system of flexible work arrangements and frequent job change "corrodes trust, loyalty, and mutual commitment" (24). It was too much of a leap, I thought, to link changes in the structure of the modern workplace and career to an alleged difficulty maintaining more permanent relationships in other aspects of life, and yet my own data now attests to that connection. My initial failure to see that link was due in part to the striking dissimilarities I observed between contemporary tech workers and their 1980s counterparts. The newer generation's more sanguine, optimistic perspective was so distinct from what I had expected to find that it obscured some of the subtler ways in which modern managers resembled their predecessors. Thus my initial conclusions, while not entirely uncritical, emphasized career management's role in sustaining jobseekers' optimism and self-esteem; it was only upon learning of jobseekers' subsequent marital struggles that I began to reread male jobseekers' initial descriptions of their successful, egalitarian marriages in more nuanced and critical ways. ${ }^{6}$

That the ideology of career management obscures and even exacerbates the damage insecure employment and prolonged joblessness have wrought on tech workers and their families is itself a significant finding. It testifies both to the resilience of neoliberalism's individualist, pro-market modes of thought and to the ongoing hardships — personal, financial, and professional — facing jobless and insecurely employed U.S. workers and their families. It also demands that we rethink many of our assumptions about the structure and meaning of white-collar work, particularly in light of dramatic cultural shifts over the previous decades around what it means to be a valued professional, a successful man, and a good husband and father. Such considerations become even more important as we struggle to make sense of, and make predictions about, the experiences of the millions of U.S. workers whose jobs were lost in the most recent economic downturn.

These specific findings, and the processes by which I reached them, have further implications for how we think about and go about doing ethnographic research. In addition to the flaws in research design I describe above, it is also simply the case that it took time for these marriages to falter under the combined weight of insecure employment, economic hardship, and the unexpected renegotiation of gender roles and responsibilities. My more than three-year field stay was long by recent standards; the unofficial one- to two-year norm established early in the twentieth century (itself an "idealized, caricatured model" (Okely 357) has recently given way to shorter durations (Wolcott 69) and what Wulff calls "yo-yo fieldwork," culled together from a series of brief site visits. While I am concerned about the general shrinking of fieldwork durations and swayed by arguments like those in 
Kemper et al. as to the benefits of long-term research projects, I do not believe all projects require extended, unbroken field stays, or that long fieldwork durations inevitably result in superior scholarship. Indeed, no matter how long one stays in the field, ending a research project is akin to putting a novel down with a few chapters to go. One may have a sense of where things are going, but cannot say for certain how the story will end. And yet we all must eventually leave the field, even if only because our tenure and promotion schedules demand that we publish our conclusions in one form or another and move on to new projects.

To return to my initial point, my experience tangibly illustrates the ways in which ethnographic research, whether three days' or three years' worth, is always incomplete, always in progress, always ripe for reconsideration. While my initial findings were not necessarily inaccurate, they were certainly partial. This ever-unfinished nature of cultural analysis can be frustrating and, at moments, discouraging. I have wondered more than once what more, what else, I might have learned with yet another bout of fieldwork. Specifically, what new features and fissures might be revealed through additional interviews and observation? Are there in fact temporal, emotional, or financial limits across which these tech workers will not be pushed? If their emotional and financial reserves eventually do run dry, will their optimistic individualism then give way to collective rage? Or is this worldview so persistent and persuasive that individual Americans and their families will continue to stoically accept whatever burdens are piled upon them, even as their bank accounts dwindle, their job prospects grow bleaker, and their personal relationships grow increasingly strained?

For those of us who make our living seeking to understand why people do the fascinating things they do, it can be discomfiting to leave such an array of questions unanswered, even if only for now. As useful as I believe it is to publicly discuss the processes by which we arrive at, refine, and occasionally discard our findings, it is difficult not to be at least slightly self-conscious when airing one's intellectual and procedural dirty laundry. It can be tempting to hide those doubts behind a mask of positivist certainty or, conversely, to declare all efforts to document the workings of a particular culture doomed before they begin. But, to employ the metaphor Geertz uses when discussing objectivity, to do so would be "like saying that as a perfectly aseptic environment is impossible, one might as well conduct surgery in a sewer" (30). Alternatively, experiences like my own might be used to demonstrate the unique challenges of cultural analysis while also impelling us in more productive directions, prodding us to design our projects more thoughtfully, schedule our field visits more carefully, and couch our findings in language that recognizes, without surrendering to, the inherent imperfection of what it is that we as cultural analysts do. Our inevitable missteps and misgivings, rather than weakening or invalidating our conclusions, can instead be used to hone and strengthen them, resulting in works that more fully and accurately reflect the complicated, inconstant nature of the world around us and the lives being lived therein.

\section{Notes}

1 See for example Kemper et al. on the advantages of long-term longitudinal studies, a topic I return to later in this article. 
2 "Phil Wright" is a pseudonym, as are the names of all interviewees quoted or discussed in this article.

${ }^{3}$ One survey found that just over half of laid-off tech workers in the greater Dallas area had a working spouse at the time of their job loss (Virick), which corresponds closely to the nation as a whole, in which more than half of all married couples include two full-time earners (Bureau of Labor Statistics 2).

${ }^{4}$ Unemployed women, in contrast, were far less comfortable relying on a spouse's income, and tended to employ a language of guilt and self-blame more similar to that of laid-off managers of the 1980s than to their male contemporaries. Elsewhere (Lane forthcoming; Lane 2009) I attribute this in great part to professional women's belated embracing of the managerial ideology of meritocratic individualism, which explains failure in exclusively individual rather than structural or political terms, at the very moment men were casting off that framework.

5 For a fuller discussion of the compensatory benefits of claiming responsibility for one's own downward mobility, see Newman 233.

${ }^{6}$ I owe Kathryn Dudley a significant debt for her role in helping me think through and hone this analysis.

\section{Works Cited}

United States. Bureau of Labor Statistics. Employment Characteristics of Families in 2007. Washington, D.C.: U.S. Department of Labor, 2008.

Davis, Clark. Company Men: White-Collar Life and Corporate Cultures in Los Angeles, 1892-1941. Baltimore: Johns Hopkins University Press, 2000.

Ehrenreich, Barbara. "Trying To Find a Job Is Not a Job." Los Angeles Times 3 May 2009. 18 June $2009<$ http://articles.latimes.com/2009/may/03/opinion/ oe-ehrenreich3>.

Frank, Thomas. One Market under God: Extreme Capitalism, Market Populism, and the End of Economic Democracy. New York: Random House, 2000.

Geertz, Clifford. The Interpretation of Cultures. New York: Basic Books, 1973.

Giroux, Henry. Public Spaces, Private Lives: Beyond the Culture of Cynicism. New York: Rowman and Littlefield, 2001.

Greenhouse, Steven. “In America, Labor Has An Unusually Long Fuse.” New York Times 5 April 2009: WK3.

Harvey, David. A Brief History of Neoliberalism. New York: Oxford University Press, 2005.

Hochschild, Arlie. The Second Shift: Working Parents and the Revolution at Home. New York: Viking, 1989.

---. The Time Bind: When Work Becomes Home and Home Becomes Work. 1997. New York: Holt, 2001.

Kemper, Robert V. and Anya Peterson Royce, eds. Chronicling Cultures: LongTerm Field Research in Anthropology. Walnut Creek, CA: AltaMira Press, 2002.

Kwolek-Folland, Angel. Engendering Business: Men and Women in the Corporate Office, 1870-1930. Baltimore: Johns Hopkins University Press, 1994.

Lane, Carrie. "Man Enough to Let My Wife Support Me: How Changing Models of Career and Gender Are Reshaping the Experience of Unemployment." American 
Ethnologist 36.4 (2009): 681-92.

---. A Company of One: Neoliberal Faith and the Post-Organization Man [working title]. Ithaca, NY: Cornell University Press, forthcoming.

Marcus, George. "How Short Can Fieldwork Be?" Social Anthropology 15.3 (2007): 353-67.

Newman, Katherine. Falling from Grace: Downward Mobility in the Age of Affluence. Berkeley: University of California Press, 1988.

Nippert-Eng, Christena. Home and Work: Negotiating Boundaries through Everyday Life. Chicago: University of Chicago Press, 1996.

Okely, Judith. "Response to George E. Marcus.” Social Anthropology 15.3 (2008): 357-61.

Sennett, Richard. The Corrosion of Character: The Personal Consequences of Work in the New Capitalism. New York: W.W. Norton \& Co., 1998.

Townsend, Nicholas W. The Package Deal: Marriage, Work, and Fatherhood in Men's Lives. Philadelphia: Temple University Press, 2002.

Uchitelle, Louis. The Disposable American: Layoffs and Their Consequences. New York: Knopf, 2006.

Venkatesh, Sudhir. "Feeling Too Down to Rise Up." New York Times 29 March 2009: WK 10.

Virick, Meghna. Research Report: The Effect of Layoffs in the North Texas Region. 2003. North Texas Technology Council and University of Texas at Arlington. 18 June $2009<$ http://www.nttc.ws/utasurvey/Layoff\%20Research\%20Report $\% 20$ -\%20FINAL.pdf $>$.

Wolcott, Harry F. The Art of Fieldwork. 2nd ed. Walnut Creek, CA: AltaMira Press, 2005.

Wulff, Helena. "Yo-yo Fieldwork: Mobility and Time in a Multi-Local Study of Dance in Ireland." Anthropological Journal on European Culture 11 (2002): 117-36. 